Journal of Education and Vocational Research (ISSN 2221-2590)

Vol. 6, No. 4, pp. 15-23, December 2015

\title{
An Online and Collaborative Learning Design model based on IMS-LD to Stimulate Collaborative Learning in E-learning Environments
}

\author{
Abderrahim EL MHOUTI*, Azeddine NASSEH, Mohamed ERRADI \\ Abdelmalek Essaadi University, Tetouan, Morocco \\ *abderrahim.elmhouti@gmail.com
}

\begin{abstract}
In the e-learning field, there is an urgent need for the sharing, reuse and design of online courses as learning objects. However, in the vast majority of cases, e-learning courses are built in a manner that not stimulating cooperation, interaction, and collaborative learning. The primary aim of this paper is to develop a strategy for constructing learning objects, strategy targeted at supporting instructors in designing educational contents in order to promote collaborative learning in e-learning environments. A key challenge in this work is the definition of a new method of learning design of e-learning contents to stimulate collaborative learning. In addition, we introduce a general model of online and collaborative learning design. Model is based on the methods of instructional design and Educational Modeling Languages, particularly the IMS-LD specification. Firstly, the paper presents the online and collaborative design process of a content based on a life cycle adapted. Then, the paper describes the steps of the modeling process of content. Finally, the paper exposes the adopted technical choices and a first prototype is set up to provide a subjective evaluation of the new framework.
\end{abstract}

Keywords: Collaborative learning, e-learning, learning design, learning object, IMS-LD

\section{Introduction}

Today, the pedagogical possibilities made possible by digital technologies constituting a main lever for the modernization of practices of e-learning. The evolution of Web 2.0 technologies and its implications in elearning allows envisaging new teaching and learning forms, giving a preponderant place to the collaboration, cooperation and social interaction (El Mhouti et al., 2014). However, the problematic of digital uses in elearning focuses today on the design of learning content: have we digital content adapted to this new type of learning: collaborative learning, socioconstructivist learning, etc.? What is being done to promote the production of quality digital content? Various studies show that, from a pedagogical point of view, these contents do not perform their function and that they are individually designed which leads to learning content little/no adapted to collaborative learning vision (Trillaud, 2013). The work presented in this paper fits in the light of these findings. It relates of the work on learning design and is focuses mainly on the processes of design of e-learning contents by means of reusable and interoperable Learning Objects (LO). This work has as main objective to search conceptual and computer solutions to designing e-learning contents promoting collaborative e-learning.

Thus, to promote collaborative learning, this work proposes a model based on socioconstructivism approach, for developing structured learning content and methodically developed, for an e-learning platform. For that, this work propose to implement an online and collaborative learning design model to modeling pedagogical contents as units of learning adapted to the IMS-LD (Learning Design) format. The collaborative learning design process takes place in a Collaborative Design Environment while the process of development takes place in the Reload Learning Design Editor tool. As a first step, this paper presents the e-learning concepts, while at focusing on its collaborative dimension: collaborative e-learning. Then, this work highlights the role of learning content in an e-learning platform. In this context, a literature review of methods and models of LD was presented, especially the IMS-LD specification, on which this work is based. In the next section, this work describes the basics of design and architecture of the proposed model. The paper then proceeds to describe the technological choices to implement the model and concludes with prospects of this research. 


\section{Literature Review}

The design of teaching and learning contents is the concern of all educational institutions at all their levels. However, several works in practical contexts show that these contents are the eternal forgotten in political reform of educational systems. Their design is done in most of the time individually (Cormier, 2012). This leads to pedagogical contents little/no adapted to social and collaborative learning vision, vision increasingly favored in e-learning (El Mhouti et al., 2013). To overcome the shortcomings raised, this work aims to establish a model of online and collaborative and online learning design and development of educational contents to stimulate collaborative learning in e-learning. Before describing the design and the implementation of the proposed model, current section is oriented towards the presentation of theoretical and methodological basic concepts which we refer in the e-learning design process.

E-learning: e-learning is the result of the integration of technologies, Internet an computers in education. Nowadays, e-learning forms the nucleus of a number of programs offered by educational institutions (Rupesh, 2009). The evolution of Web 2.0 technologies has spawned e-learning 2.0. The impact of practices on the Web has led to a new range of services that can be called eLearning 2.0.

Figure 1: Different forms of e-learning (Bates, 2011)

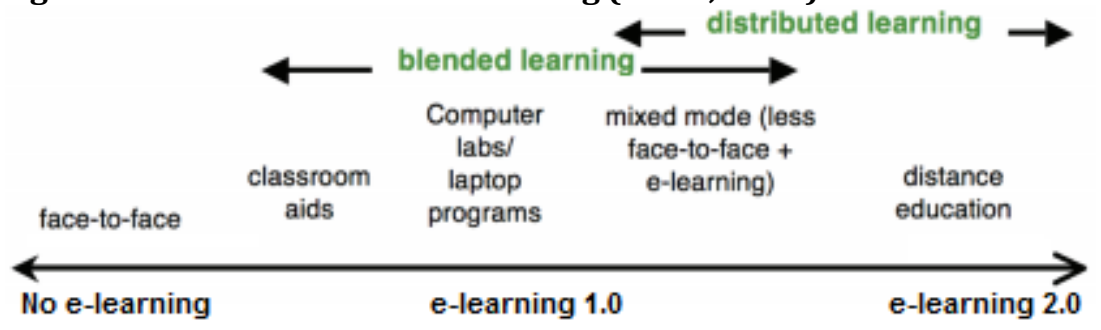

E-learning 2.0 represents the second version of e-learning relying on Web 2.0 technologies and new trends of e-learning like collaborative e-learning. e-learning 2.0 relies on the creation and sharing of knowledge with various users using tools such as wikis, blogs, social networking and social bookmarking to support collaborative learning practices (Rupesh, 2009).

Collaborative e-learning: Collaborative learning (CL) is a learning method which involves effort of learners and teachers. In this approach, learners are working in groups on case-based learning, problem-based, discussions and other ways where learners are actively participate in the learning process. In e-learning environments, learning as a collaborative way where learners must reflect, discuss, gather and analyze information promotes practices of collaborative e-learning. The aim of the courses in collaborative learning environments is to help the learner to learn from others and share knowledge and information (Anne \& Grete, 2009). Traditionally, e-learning courses are designed and built individually, manner that not promote, collaboration, cooperation and interaction. This is why these courses must be adapted to this new type and context of learning.

E-learning content-design process, methods and tools: The changes performed by Web technologies are determinant when it comes to the subject of the educational act: the pedagogical content. However, the implementation of content suited to the collaborative learning context cannot succeed without the taking into account, in addition to the constraints of costs and time, some pedagogical and technical aspects. One of the main aspects concerns the design process of such content. Although most of what we see as individual learning becomes collaborative, and spite of the diversity of actors involved, the design of contents is done in most of the time individually (Trillaud, 2013). Another aspect concerns the mechanisms for implementing pedagogical contents using learning objects. In this context, the important international movement to establish pedagogical standards and norms for e-learning has changed the way that we exercise the practices of learning design (Wiley, 2002).

Learning Design process: LD (Learning Design) consists in describing the learning and teaching process following a pedagogical approach that addresses objectives of learning for a particular audience in a particular 
discipline (Koper \& Olivier, 2004). Figure2 illustrates the relations among the Unit of Learning (UoL: a concept increasingly used in the field of the LD), learning model, domain model, and theories of learning and instruction. The UoL is the result of the LD process.

Figure 2: The context of learning design (Koper $\&$ Miao, 2008)

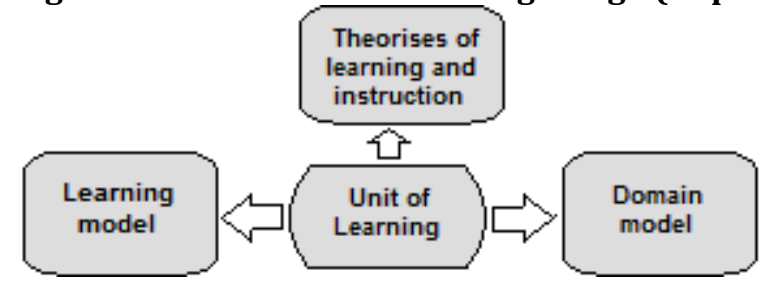

The learning model describes how students learn based on various learning theories. The domain model describes the content and its organization, for example, software engineering or data on the Web. The theories of learning and instruction describe the instruction principles and models based on the literature or the experience of practitioners (Koper \& Miao, 2008). In e-learning systems, to allow the conception of the dynamic of learning and teaching and their standardization, the Consortium IMS-Global Learning has set a new specification for implementing e-learning courses: IMS-LD (IMS-Learning Design). In the following, we describe in detail this specification.

Instructional Management Systems-Learning Design (IMS-LD): IMS-LD is an e-learning standard used to build digital courses, known as Unit of Learning (UoL), in a semantic, reusable, interoperable and formal fashion. This is a specification to design and encode learning structures (IMS-LD, 2003). The IMS-LD supports a various pedagogical methods like collaborative, active and adaptive learning (Koper \& Olivier, 2004). The life cycle begins with a lesson plan modeled according to IMS-LD, and defining services, activities, roles and many other elements within an XML document (Burgos et al., 2007).

The conceptual structure of IMS-LD is composed of 3 main levels (Figure 3):

- Level A: it is the basis of IMS-LD, and provides baseline elements to construct any UoL;

- Level $B$ : it adds others functionalities to build complex lessons and courses;

- Level $C$ : it adds the concept of notifications.

Figure 3: Three levels of the IMS-LD specification

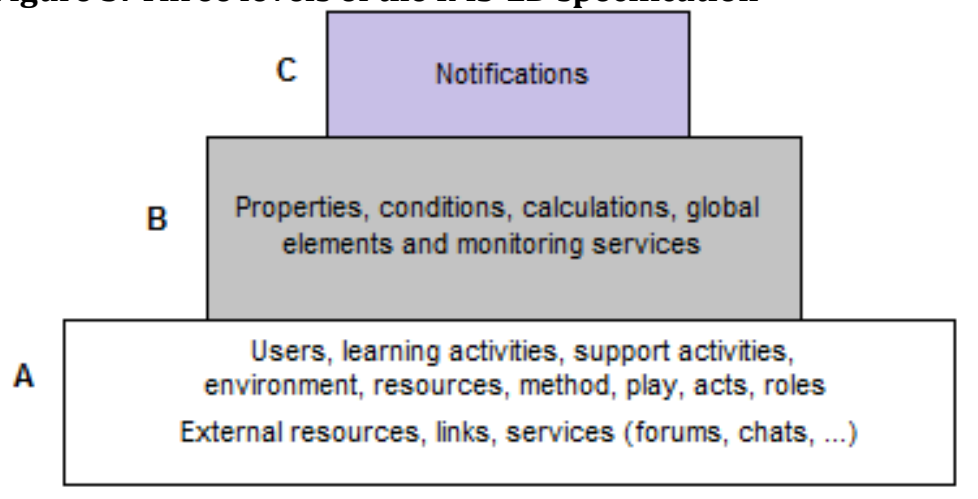

The use of the IMS-LD specification requires an authoring tool environment compatible with this specification. In this sense, several existing tools and editors can be used to design and create UoL such as: Cosmos, Reload Learning Design Editor, Copper Author, etc.

\section{An Online and Collaborative Learning Design model to develop e-learning contents}

In e-learning systems, learn collaboratively is not always easy when digital courses are not adapted to this type of learning. However, one way to reduce these problems and stimulate collaborative e-learning is to design contents according to an Online and Collaborative Learning Design (OCLD) process promoting interactions 
between teachers-authors. In this section, we will define and explain the foundation on which rests the implementation of the Online and Collaborative Learning Design model and we continue by describing its conceptual architecture and technical choices adopted to implement it.

The collaboration in the content learning design process: The term "collaboration" has different meanings depending on who uses it and in what circumstances. In some projects, "collaboration" simply means that the persons concerned are involved in the project activities. In the most advanced cases of collaboration, it means the act of working together to achieve a goal. In common sense, collaboration is a process by which two or more persons or organizations join forces to achieve a work. The practice of collaboration in the design of educational content means that teachers and trainers concerned are actively involved in the different stages of the design phase rather than produce these contents individually. Thanks to the information and experiences exchanges, collaboration in the design of educational content brings together the maximum of experiences and opinions. In this context, and in order to promote collaborative learning practices, teachers can make a very practical contribution to the process of e-learning content design by working collaboratively online. This leads to the production of quality content, too much pushed to the activity and which meet the needs of learners in terms of "collaboration".

\section{Online and Collaborative Learning Design model}

Description: In the proposed model, online and collaborative design process of contents is similar to what we find in the software engineering. The collaborative design is assured according to a life cycle adapted, following to an incremental process broken down into several phases which correspond to a set of tasks to perform collaboratively. The use of a life cycle brings several advantages: promotes traceability, improves the visibility on the content evolution and promotes the constitution of groups of collaborative work (Catteau \& Vidal, 2008). Indeed, evoke the concept of life cycle to develop e-learning contents returns to adapt to the educational context methods from industry. In this sense, the first advantage of adopting a lifecycle to implement e-learning content will thus reducing the time and therefore costs of development of such contents (Figure 4).

Figure 4: From the individual to the collaborative learning design process

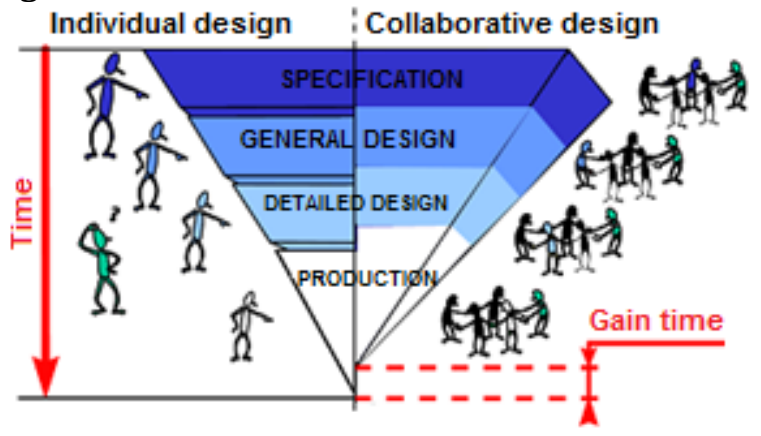

Besides the advantages mentioned above, in the proposed online and collaborative learning design method, the actors involved in the different stages work together. They are moving towards a partial parallelism throughout this process.

Collaborative design life cycle: Considering its advantages, the choice fell on the model known as "V-Cycle". The strong point of this model is that any description of a pedagogical component is accompanied by tests, which will ensure that it matches its initial description. Figure 5 illustrates the steps of the collaborative design process of contents. 


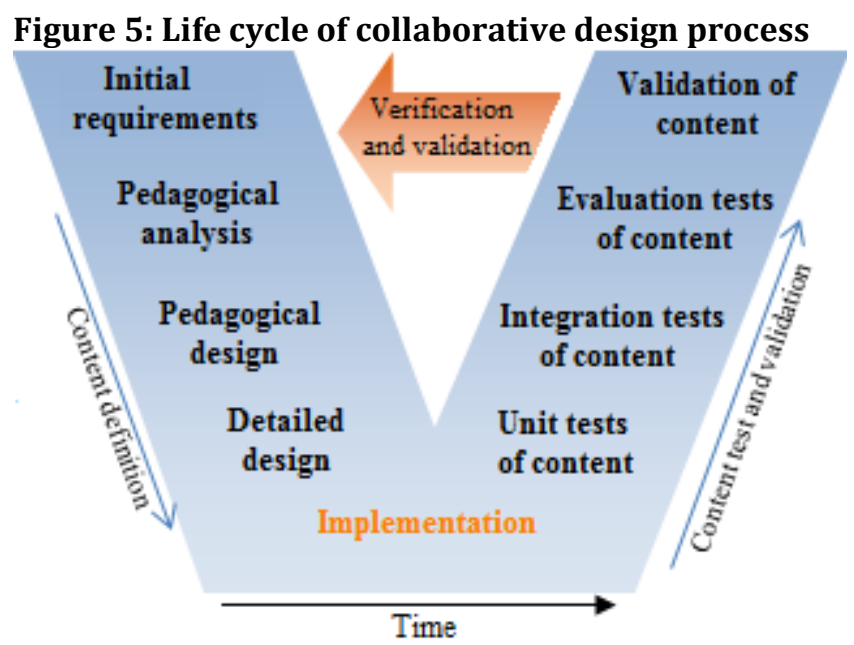

The collaborative design process is done in natural language and through descriptive texts and schemas. On completion of this process, the authors must have a database of detailed e-learning resources and e-learning contents. In the next section, we describe in more detail the main phases of the educational model of OCLD of e-learning contents.

Main phases: The Online and Collaborative Learning Design process proposed is composed of three main steps:

- collaborative design;

- collaborative production;

- Diffusion of learning objects produced.

In each step, a graphical interface and a set of tools used to complete the corresponding task: pedagogical task, didactic task, mediatic task and technological task. Figure 6 shows the process of generating of contents packages as learning objects.

Figure 6: Collaborative design process phases

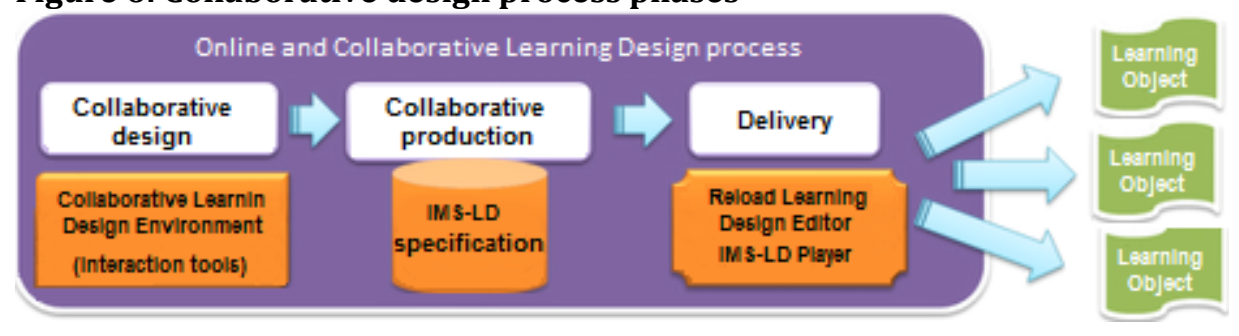

The collaborative design phase takes place in an online space called "Collaborative Design Environment" (CDE). In this space, teacher's authors develop a structured and hierarchical representation of concepts and knowledge to teach and model the learning paths, scenarios and possible sequences. The collaborative production phase concerns the mediatization of learning paths and scenarios developed in the previous step. Here, the units of learning are produced according to IMS-LD format. Teacher authors consult a resources management system to select a mediatic object (image, video, animation, etc.) previously created and saved in database. Every selected mediatic object is linked with one or more acts. The last phase of the collaborative design process is that of content delivery as standard learning objects. To facilitate this task, it was proposed to use the authoring called Reload Learning Design Editor (that we will present in detail in the next section).It is a scenario development tool to generate the executable version of the learning object compatible to IMS-LD format to ensure reusability and interoperability. Note also that at the end of this process of online and collaborative design, the teacher author can make changes on all stages. 


\section{Conceptual structure}

The general structure of the proposed Online and Collaborative Learning Design model of e-learning courses is based on two complementary parts: 1 / design part, which is done in collaboration between the various actors according to the $\mathrm{V}$ life cycle; and 2/ development part, to create units of learning as learning objects compatible with IMS-LD format. Figure 7 illustrates the general structure of the model.

\section{Figure 7: Architecture of the proposed model}

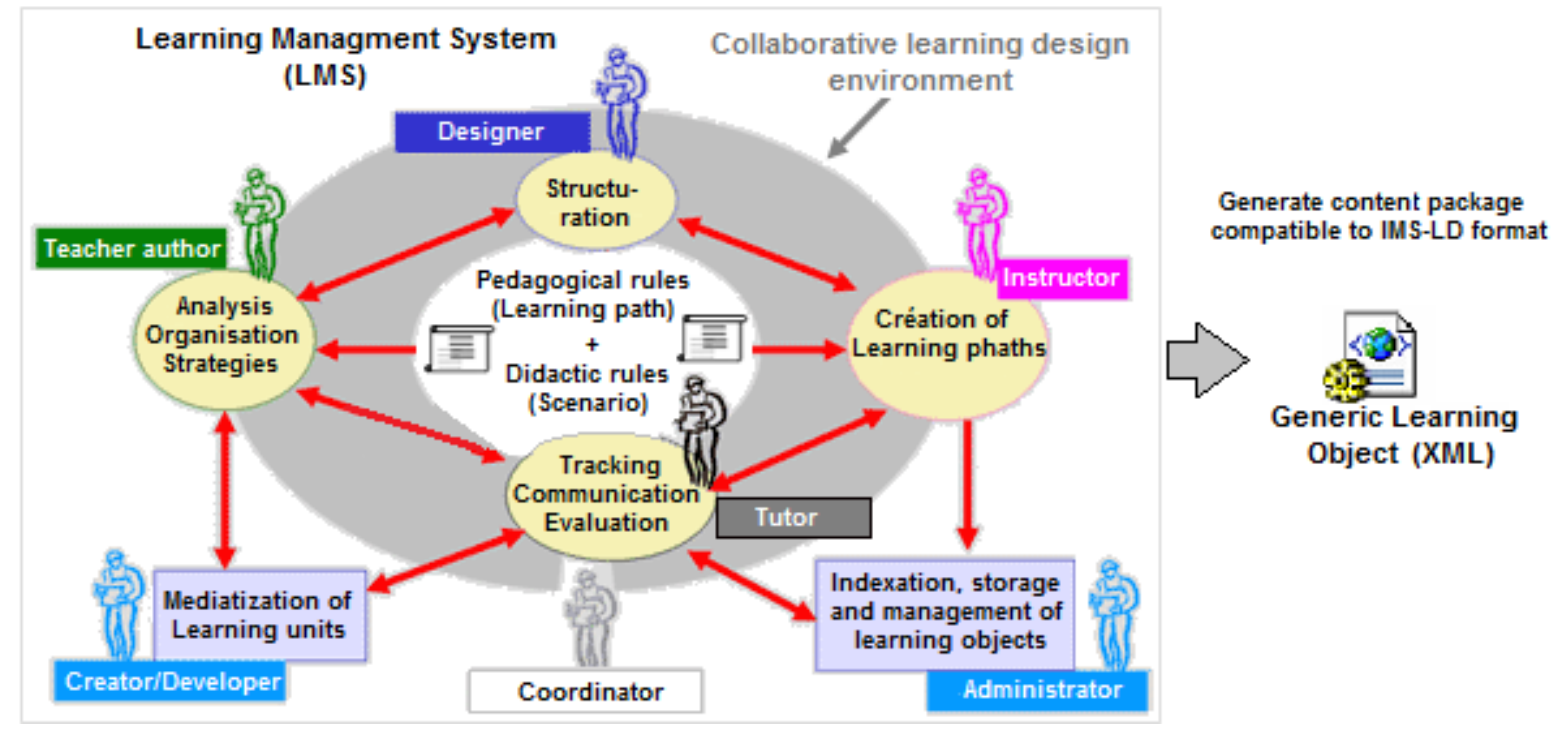

In this architecture, we can distinguish two tasks performed by the staff of authors/designers (authorsteacher, designer, developer, coordinator, etc.):

- Design task: this task concerns two roles carried out by members of the staff according to their specialty: pedagogical role and didactic role.

- Development task: this task also concerns two functions exercised by the members of the staff: technical role and mediatic role.

The design task takes place in the CDE. This space aims at making available to teachers an environment which allows many possibilities. This is an LMS (Learning Management System) providing two main functions. Firstly, this LMS offers the online Collaborative Design Environment and thus implements the Online and Collaborative Learning Design process proposed. Through this space, collaborative design is facilitated by exchange and sharing of information, participation in forums, use of videoconference and other tools of synchronous/asynchronous communication. Secondly, this area is responsible for everything related to management: it manages the contents and educational resources, author's profiles, registration, etc. After the design of the UoL, the staff starts development task. Among many standards analyzed, the IMS-LD was used to create UoL and generating learning paths. We have adopted this specification for modeling UoL because it is a formal pedagogical standard accounted the most popular language for describing learning design. Its strength is that it focuses on the "scenario" more than the "aggregation" of content/resources, and it formally dissociates "activity" and "resource" by specifying the semantic relations linking them. At the end of the online and collaborative design-development process, author creates the executable version of the learning object produced. This task is done using the authoring tool Reload Learning Design Editor (RLDE) (Figure 8). It should be noted also that it is a modeling using the adaptive level of IMS-LD (level A). 


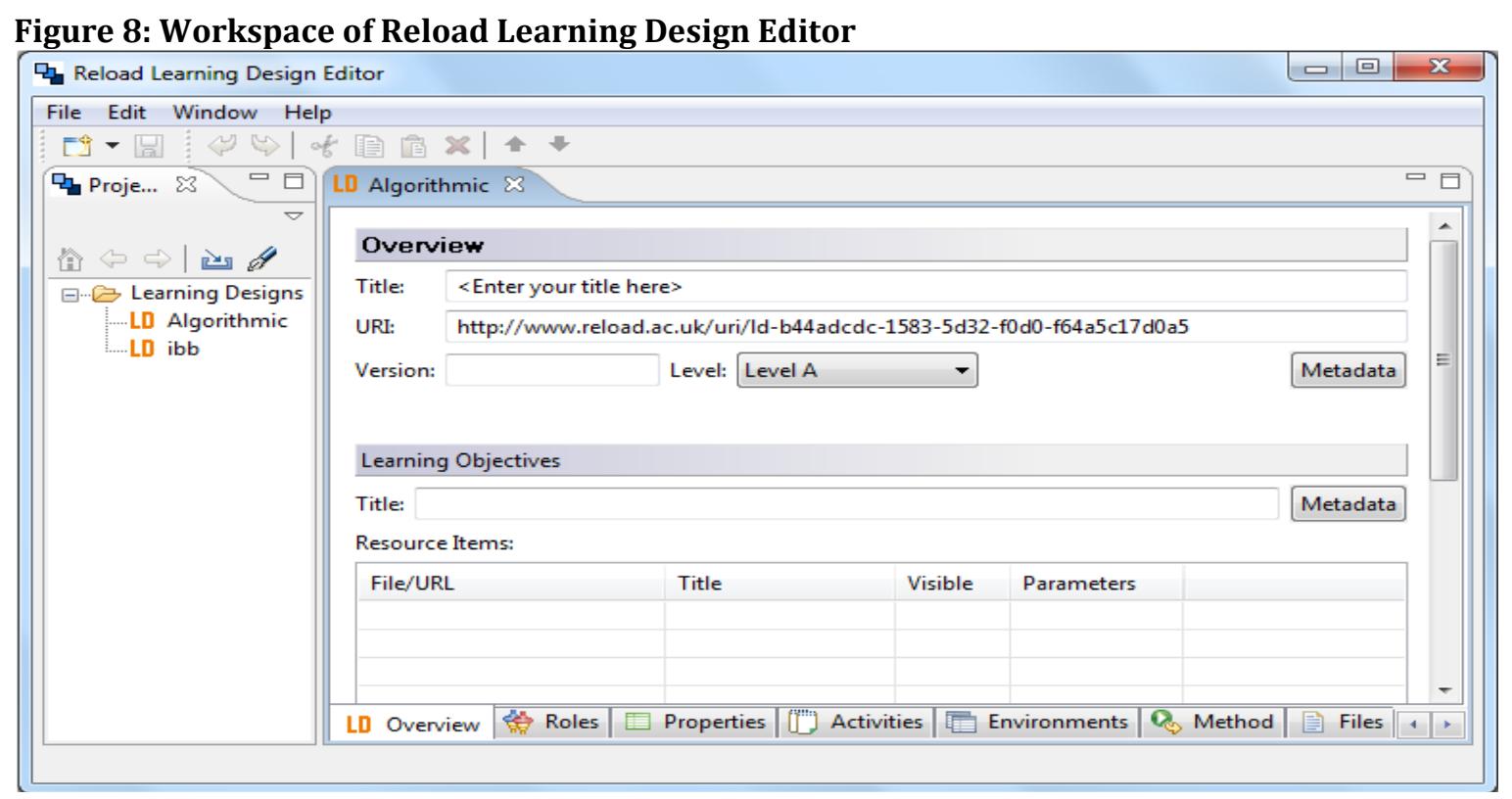

The $R L D E$ is an authoring environment developed in Java language. It is an open source and tree-based LD editor tool used to build UoL compatible to the IMS-LD format (Milligan et al., 2005).

Implementation: To implement the proposed online and collaborative learning design model, the choice of technologies is based on the reuse and the linking of many existing software solutions. Thus, we have setting up an LMS ensures two main functions: 1/ integrates Online and Collaborative Design Environment; and 2/ manages resources, courses, users accounts, etc. In addition, this LMS offers a teacher environment and a learner environment. The software design of the proposed model is based on technology choices on which rest the development of modern forms of distance training (Web 2.0 technologies). Thus, after comparative studies conducted, the $C D E$ is implemented using the LMS Dokeos (version 2.1). It is an LMS developed in PHP and built around a client-server architecture. It is accompanied by a software called "Dokeos Mind" facilitating the representation and design of educational content in the form of concept maps, and very useful in the design phase. The $C D E$ offers a rich online space that allows facilitating and organizing exchanges between teacher's authors/designers. Figure 9 shows an overview of tools available in $C D E$.

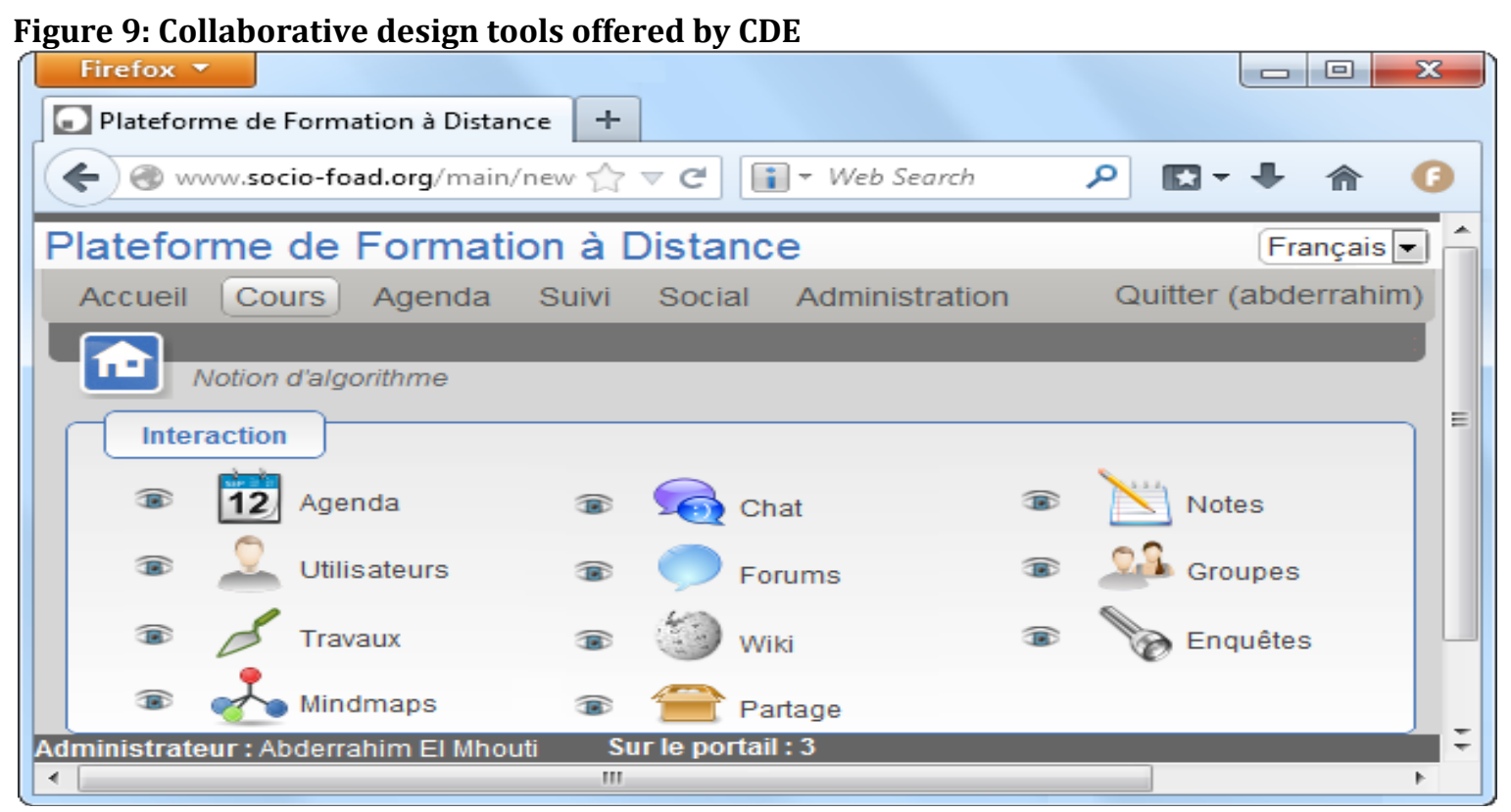


The features of Dokeos ensure maximum interactivity between teacher-authors. They help to plan online meetings and video-conferences. These tools make it easy to organize online discussions and do not require additional installation on the teacher-author's computer. To support the IMS-LD standard, we have oriented our work towards the management and exploitation of educational content by implementing an export and import mechanism in IMS-LD format. That's why we have added to the platform Dokeos an runtime environment of learning objects compatible with this format. Indeed, in Dokeos, the features are implemented separately in the form of modules (like chat, documents, quiz, forum, etc.). This provides the opportunity to create and integrate new formats for Dokeos courses. Thus, in order to support courses compatible to the IMS-LD format, a new format of courses has been implemented in Dokeos to provide functionalities to use this LMS as a runtime environment for learning units consistent with IMS-LD Level A. Figure 10 illustrates the new architecture of Dokeos to support IMS-LD format, with extended components marked in grey.

\section{Figure 10: Integration into Dokeos of a prototypical runtime environment of LMS-LD}

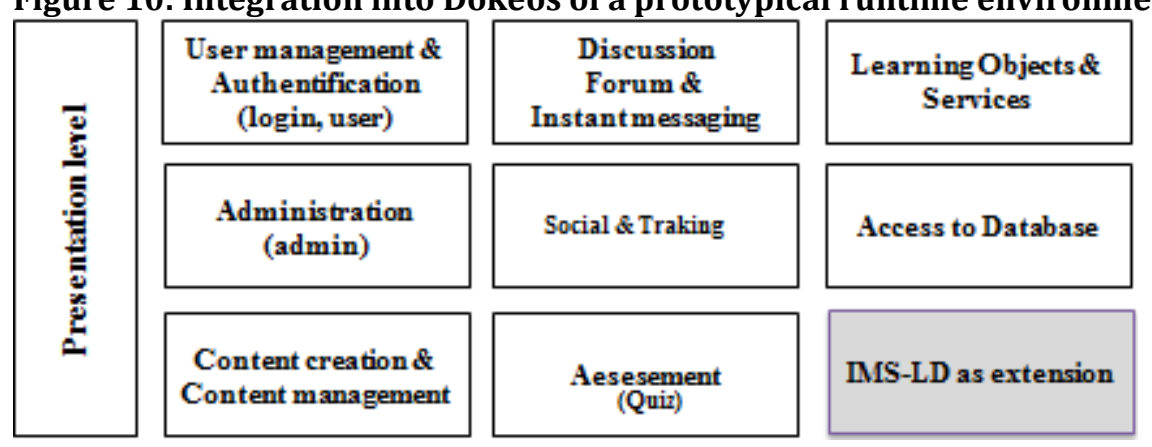

Following the structure of the level A of IMS-LD, the e-learning courses structure is constructed from activities, activity structures, acts and plays. Mediatic resources (images, videos, animations, etc.) for learning are add to the IMS-LD environment and are linked to activities. Designers can edit the imsmanifest.xml file and thus practice learning design process by implementing learning activities organized in structures, acts and plays. The graphical interface of the LMS Dokeos provides various views of the digital course structure, based on the user choice and its role and the progress in the teaching-learning. For this, the information contained in the imsmanifest.xml file to run UoL is treated (through XSL) and presented to learners and teachers.

\section{Conclusion}

The high costs of design and development in e-learning and the challenge of restraining those costs cannot be denied. However, the purpose for which this type of learning was created cannot be ignored: the collaborative learning without constraints of time and place. In this research work, we have presented a general model for Online and Collaborative Learning Design based on IMS-LD specification. The objective is to provide design support for teachers-authors and instructors to promote collaborative learning in e-learning systems. The Online and Collaborative Learning Design process, which takes place in an online collaborative design environment, is ensured following a generic life cycle that we have adapted to the design of teaching/learning contents (life cycle $\mathrm{V}$ ) according to an incremental process broken down into tasks to perform collaboratively. A novel aspect of this approach is that the collaborative learning design process is becoming less the product of a single author, but this is a team work, consists of a manager who ensures the educational coordination (coordinator) and several teachers (authors) who design educational contents. The authors, freed from the constraints of time and place, must work together, pool their efforts and exchange relevant data. They may also be required to collaborate with external teams of experts, multimedia and graphic designers, instructional designers, etc. The modeling of units of learning is done using the Reload Learning Design Editor, an authoring tool to facilitate the generation of learning objects reusable, interoperable and compatible to IMS-LD format. As part of the continuity of this work, we are working on the extension of the model to integrate the levels B and C of the IMS-LD specification. On the other hand, we have planned to develop an authoring environment to collaboratively modeling of UL by implementing real-time collaboration on the different steps of learning design process. The authoring environment will be developed from Web 2.0 
perspective by implementing necessary techniques for synchronization of the content published by users (teachers-authors).

\section{References}

Anne, K. L. \& Grete, O. H. (2009). Collaborative learning in e-learning, Virtual book e-pedagogy for teachers in higher education, Bergen University College, Bergen, Norway.

Bates, T. (2011). Understanding Web 2.0 and its Implications for e-learning. Web 2.0 based e-learning: Applying Social Informatics for Tertiary Teaching, 21-42.

Burgos, D., Tattersall, C., Dougiamas, M., Vogten, H. \& Koper, R. (2007). A First Step Mapping IMS Learning Design and Model. Journal of Universal Computer Science, 13(7), 924-931.

Catteau, 0. \& Vidal, P. (2008). Le Cycle de Vie de l'Objet Pédagogique et de ses Métadonnées, Doctoral dissertation, Paul Sabatier University, France.

Cormier, L. (2012). Le soutien au développement de ressources numériques pour l'enseignement et l'apprentissage dans les universités québécoises, In proceedings of the 80ème Congrès de l'ACFAS.

El Mhouti, A., Nasseh, A. \& Erradi, M. (2013). An Evaluation Model of Digital Educational Resources. International Journal of Emerging Technologies in Learning, 8(2), 29-35.

El Mhouti, A., Nasseh, A. \& Erradi, M. (2014). Design and implementation of a Socioconstructivist Model of Collaborative Learning Design (SMC-LD) dedicated to distance learning. International Journal of Computer Sciences and Engineering, 2(8), 1-10.

IMS Global-LC. (2015). IMS Global Learning Consortium, Website: http://www.imsglobal.org/learningdesign/

(IMS-LD, 2003) IMSLD: IMS Learning Design. (2003). Available at: http://www.imsglobal.org/learningdesign/index.cfm

Koper, R. \& Olivier, B. (2004). Representing the learning design of units of learning. Educational Technology \& Society, 7(3), 97-111.

Koper, R. \& Miao, Y. (2008). Using the IMS LD Standard to Describe Learning Designs. In: Lockyer, L., Bennet, S., Agostinho, S. and Harper, B. (Eds.), Handbook of Research on Learning Design and Learning Objects: Issues, Applications and Technologies (pp. 41-86). IDEA group.

Milligan, C. D., Beauvoir, P. \& Sharples, P. (2005). The Reload Learning Design Tools. Journal of Interactive Media in Education (Advances in Learning Design. Special Issue, eds. Colin Tattersall, Rob Koper), 2005/07. ISSN: 1365-893X.

Rupesh, K. A. (2009). E-Learning 2.0: Learning Redefined, Library Philosophy and Practice, ISSN 1522-0222.

Trillaud, F. (2013). Architecture pour le contrôle des interactions et le pilotage d'une application interactive multi-utilisateurs à exécution adaptative : application à un environnement de FOAD, Doctoral dissertation, University of La Rochelle, France.

Wiley, D. A. (2002). Connecting learning objects to Instructional design theory: a definition, a methaphor, and taxonomy. In Wiley (Ed), the Instructional Use of Learning Objects. Agency for Instructional Technology and Association for Educational Communications of Technology, Bloomington, Indiana.

\section{List of non-standard abbreviations}

OCLD: Online and Collaborative Learning Design

CDE: Collaborative Design Environment

UoL: Unit of Learning

RLDE: Reload Learning Design Editor

LO: Learning Object

LD: Learning design 